\title{
A Model of Financial Market Liquidity Based on Intermediary Capital *
}

\author{
Denis Gromb \\ INSEAD and CEPR
}

\author{
Dimitri Vayanos \\ London School of Economics \\ $C E P R$ and NBER
}

This draft: November 26, 2009

\begin{abstract}
We present a model of financial market liquidity provided by financially constrained intermediaries. We show that market liquidity increases with the level of intermediary capital. We also characterize conditions under which intermediaries play a stabilizing or destabilizing role in markets. Finally, we sketch a number of areas, including welfare and public policy, on which the model can shed light.
\end{abstract}

Keywords: Financial crises, financial constraints, arbitrage, liquidity, amplification, contagion, welfare, public policy.

JEL: G01, G11, G12, G18, G21, G15.

\footnotetext{
${ }^{*}$ Correspondence: Denis Gromb, denis.gromb@insead.edu and Dimitri Vayanos, D.Vayanos@lse.ac.uk. We thank participants at the EEA 2009 meetings in Barcelona and an anonymous referee for comments. All remaining errors are ours.
} 


\section{Introduction}

The recent crisis has highlighted the importance of intermediary capital for the liquidity of financial markets. As banks incurred large losses in the subprime market, they curtailed their funding of other activities, notably of other financial intermediaries, causing liquidity to dry up in many otherwise unrelated markets. Central banks around the world struggled to deal with a combined banking liquidity and financial market liquidity crisis.

Standard financial market models are ill-suited to analyze liquidity problems and related public policy issues. Indeed, asset prices in these models are determined from a representative agent, and there is no role for financial intermediaries. Therefore, the capital available to intermediaries is irrelevant for asset prices and market liquidity. Moreover, since the equilibrium is Pareto optimal, there is no scope for public policy.

We present a simple model (Section 2) in which equilibrium market liquidity is imperfect and depends on intermediary capital (Section 3). Building on the recent literature on the limits to arbitrage, we start from the premise that some sophisticated individual or institutional investors are uniquely able to identify and exploit some profitable trades reflecting the unsatisfied demand for liquidity of other, less sophisticated investors. These arbitrageurs are to be understood as individuals and institutions responsible for providing liquidity in different financial markets. At the same time, the arbitrageurs face financial constraints limiting their investment capacity, which in turn determines market liquidity. Specifically, we model arbitrageurs providing liquidity across two segmented markets but facing collateral-based financial constraints. The combination of arbitrageurs' unique ability and of their financial constraints creates a role for their capital. When arbitrage capital is high, markets are liquid. When it is low, liquidity dries up. Based on this analysis, we identify conditions under which arbitrageurs increase their positions in response to an adverse shock, thus helping stabilize the market, and when instead they are forced to liquidate their positions, thereby amplifying the shock.

Section 4 identifies directions in which the model can be extended. First, we discuss how contagion can arise between otherwise unrelated markets. Second, we sketch some welfare implications. Indeed, arbitrageurs can fail to follow socially optimal investment strategies, i.e., the equilibrium may not be constrained efficient. This result opens the door for a discussion of policy.

Our analysis builds on the recent literature on the limits to arbitrage 
and, more particularly, on financially constrained arbitrage. ${ }^{2,3}$ Gromb and Vayanos (2002) introduce a similar model in a dynamic setting, i.e., they consider explicitly the link between arbitrageurs' past performance and their ability to provide market liquidity, and how arbitrageurs take this link into account in their investment decision. They also conduct a welfare analysis. The present paper uses a simpler version of the model, but studies explicitly the stabilizing vs. destabilizing role of arbitrageurs in financial markets.

In a general formulation of equilibrium with collateral and margin contracts, Geanakoplos $(2003,2009)$ shows how these contracts arise endogenously and how they can amplify price effects. Gromb and Vayanos (2002)'s model is extended to multiple investment opportunities in a static setting by Brunnermeier and Pedersen (2009), and a dynamic one by Gromb and Vayanos (2009a). Both show how financial constraints imply that shocks propagate and liquidity co-moves across markets. A related mechanism is described in Pavlova and Rigobon (2008). In Xiong (2001) and Kyle and Xiong (2001), amplification and contagion effects arise from arbitrageurs' wealth-dependent risk aversion rather than financial constraints.

\section{The Model}

We model the role of intermediary capital for financial market liquidity. Situations of unsatisfied liquidity demand offer opportunities to sophisticated investors (arbitrageurs) uniquely able to intermediate trades. However, financial constraints limit the arbitrageurs' ability to provide market liquidity. Liquidity is therefore imperfect and depends on arbitrage capital.

\subsection{Liquidity Demand}

There are two dates $t=1,2$. There is a riskfree asset, yielding an exogenous return 0 , and two risky assets, $A$ and $B$, yielding identical payoffs and trading in segmented markets, $A$ and $B$.

In market $i=A, B$, investors are competitive and form a measure one continuum. At $t=1$, these investors, whom we call $i$-investors, can invest

\footnotetext{
${ }^{2}$ Alternative theories of the limits to arbitrage are based on frictions such as holding costs (e.g., Tuckman and Vila (1992), Kondor (2009)), search costs (e.g., Duffie and Strulovici (2009)), or incentive problems in delegated portfolio management (e.g., Shleifer and Vishny (1997), Krishamurthy and He (2009a,b)).

${ }^{3}$ We discuss our paper's relation to only the closest literature. Gromb and Vayanos (2002, 2009a,b) contain more detailed descriptions of the relevant literature.
} 
in a single risky asset, asset $i$, and in the riskfree asset. For instance, $A$ investors cannot take a position in asset $B$. Market segmentation is taken as given, i.e., investors in one market are assumed to face prohibitively large transaction costs for investing in the risky asset in the other market. The costs can be due to (unmodeled) information asymmetries, institutional constraints, etc.

We assume that assets $A$ and $B$ are in zero net supply and pay a single and identical dividend at $t=2$ equal to $\delta=\bar{\delta}+\epsilon$, where $\bar{\delta}>0$ is a constant, and $\epsilon$ is a zero-mean random variable revealed at $t=2$, and symmetrically distributed around 0 over the finite support $[-\bar{\epsilon},+\bar{\epsilon}] .{ }^{4}$

The $i$-investors have initial wealth $w_{i, 1}$ at $t=1$ and exponential utility over their wealth $w_{i, 2}$ at $t=2$, i.e., $-\exp \left(-\alpha w_{i, 2}\right)$ with $\alpha>0$ constant.

At $t=2$, each $A$-investor receives an endowment shock $u \cdot \epsilon$ with $u>0$ constant, while each $B$-investor receives the opposite shock $-u \cdot \epsilon$. Since $u>$ $0, A$-investors' ( $B$-investors') shock is positively (negatively) correlated with the dividend $\delta$, making them more (less) averse to holding the risky asset. ${ }^{5}$ The greater $u$, the greater the difference in $A$ - and $B$-investors' aversions to holding the risky asset, and the greater their potential gains from trade: $A$-investors want to sell asset $A$ and $B$-investors want to buy asset $B$. Hence, all else equal, $u$ is a measure of liquidity demand - a demand a priori frustrated by market segmentation.

\section{$2.2 \quad$ Liquidity Supply}

$A$ - and $B$-investors' unsatisfied demand for liquidity creates a role for individuals or institutions able to provide such liquidity, which we call arbitrageurs. We model arbitrageurs as sophisticated specialists who, unlike other investors, are able to invest in all risky assets as well as in the riskfree asset. They represent not only professional arbitrageurs such as hedge funds and banks' proprietary trading desks, but more generally financial intermediaries such as dealers or investment banks. Since assets $A$ and $B$ pay the same dividend, any price discrepancy between them constitutes an arbitrage opportunity, which arbitrageurs can exploit. Going long the cheaper asset $A$ and short the pricier asset $B$, arbitrageurs also act as intermediaries between $A$ - and $B$-investors, supplying liquidity to them.

\footnotetext{
${ }^{4}$ The bounded support assumption plays a role for the financial constraint (see below). Less importantly, it also implies that for $\bar{\delta}$ large enough, dividends remain positive.

${ }^{5}$ For consistency with the zero net supply assumption, the endowments can be seen as positions in a different but correlated asset, e.g., labor income. This specification is common in market microstructure models. See, e.g., the survey by Vayanos and Wang (2009)
} 
Arbitrageurs are competitive and form a measure one continuum. They have wealth $W_{1}$ at $t=1$ and a utility increasing in wealth $W_{2}$ at $t=2 .{ }^{6}$

We assume that arbitrageurs face financial constraints: They can borrow only via margin accounts that are both fully separate across risky assets and fully collateralized. To borrow and long a share of asset $A$, an arbitrageur must open a margin account and post until $t=2$ both the share of asset $A$ and further collateral (a "haircut"). Full separation means that he cannot use a position in asset $B$ as collateral, i.e., the haircut must be in the riskfree asset. Full collateralization means that the haircut must be sufficient to make the loan riskfree. Similarly, to short asset $B$, arbitrageurs must borrow and sell a share of asset $B$ and post as collateral the sale's proceeds and a haircut in the riskfree asset (not asset $A$ ) making the loan riskfree. ${ }^{7}$

\section{Market Liquidity and Intermediary Capital}

Definition 1 A competitive equilibrium consists of date $t$ prices $p_{i, t}$ for asset $i=A, B$, and risky asset holdings $y_{i, t}$ for $i$-investors, and $x_{i, t}$ for arbitrageurs, such that given the prices, each $i$-investor and arbitrageur's holdings are optimal, and the risky assets' markets clear, i.e., $y_{i, t}+x_{i, t}=0$.

Note that since all uncertainty is resolved at $t=2$, both assets trade at the same price at that date, i.e., $p_{A, 2}=p_{B, 2}=\delta$.

Definition $2 A$ competitive equilibrium is symmetric if at $t=1$, for assets $A$ and $B$ the risk premia are opposites $\left(\phi_{1} \equiv \bar{\delta}-p_{A, 1}=p_{B, 1}-\bar{\delta}>0\right)$, as are the arbitrageurs' holdings $\left(x_{1} \equiv x_{A, 1}=-x_{B, 1}\right)$ and the holdings of $A$ and $B$-investors $\left(y_{1} \equiv y_{A, 1}=-y_{B, 1}\right)$.

We can show that a symmetric competitive equilibrium exists. Indeed, the risk premia are opposites because assets are in zero net supply and

\footnotetext{
${ }^{6}$ By fixing the measure and wealth of the arbitrageurs, we rule out entry in the arbitrage industry. This seems a reasonable assumption at least for understanding shortrun market behavior. An alternative interpretation is that after $t=2$, enough new capital enters to eliminate the arbitrage opportunity. $W_{t}$ should be understood as the pool of capital, internal or external, which arbitrageurs can access fast and frictionlessly.

${ }^{7}$ The constraint, inspired by standard margin accounts, is exogenous. A model of endogenous (e.g., information-based) constraints is desirable but beyond this paper's scope. The notion that margin requirements are endogenously chosen to prevent default appears in the general equilibrium literature (e.g., Geanakoplos $(2003,2009)$ ). The model can be extended to allow for only partial collateralization (e.g., VaR-type constraints) and only partial separation (e.g., some cross-margining) at the cost of some complexity. Some degree of collateralization and separation is however needed for the constraint to be material.
} 
the endowment shocks of the $A$ - and $B$-investors are opposites. The arbitrageurs' positions are opposites because the risk premia are opposites.

Note that arbitrageurs act as intermediaries. Indeed, they buy asset $A$ from $A$-investors, and sell the same amount of asset $B$ to $B$-investors, providing these investors with the liquidity they crave. Note also that asset $A$ 's risk premium equals half the price wedge between assets $A$ and $B$, i.e.,

$$
\phi_{1}=\frac{p_{B, 1}-p_{A, 1}}{2} .
$$

It constitutes an inverse measure of market liquidity. Perfect liquidity corresponds to markets $A$ and $B$ being integrated, and hence to $\phi_{1}=0$.

$A$ - and $B$-investors. At $t=1$, each $A$-investor chooses a holding $y_{1}$ of asset $A$ to maximize the expected utility $-E_{1} \exp \left(-\alpha w_{A, 2}\right)$ subject to the budget constraint which is as follows. At $t=1$, each $A$-investor invests $y_{1} p_{A, 1}$ in asset $A$ and the rest of his wealth, $\left(w_{A, 1}-y_{1} p_{A, 1}\right)$, in the riskfree asset. By $t=2$, the investor has received an endowment $u \epsilon$. Hence

$$
\begin{aligned}
w_{A, 2} & =y_{1} p_{A, 2}+\left(w_{A, 1}-y_{1} p_{A, 1}\right)+u \epsilon \\
& =y_{1}(\bar{\delta}+\epsilon)+\left(w_{A, 1}-y_{1}\left(\bar{\delta}-\phi_{1}\right)\right)+u \epsilon \\
& =w_{A, 1}+y_{1} \phi_{1}+\left(y_{1}+u\right) \epsilon .
\end{aligned}
$$

The term $w_{A, 1}$ is the investor's wealth at $t=1$. The term $y_{1} \phi_{1}$ is the investor's expected capital gain between $t=1$ and $t=2$. The term $\left(y_{1}+u\right) \epsilon$ is the risk $A$-investors bear. It is the product of the dividend risk $\epsilon$ times the exposure $\left(y_{1}+u\right)$ of $A$-investors to that risk. The exposure $\left(y_{1}+u\right)$ arises because of the investors' position in asset $A$ and of their random endowment.

Lemma 1 A function $f$ positive, such that $f(-y)=f(y)$, and strictly convex exists such that each $A$-investor's problem at $t=1$ is:

$$
\max _{y_{1}} w_{A, 1}+y_{1} \phi_{1}-f\left(y_{1}+u\right)
$$

This result (Gromb and Vayanos (2002)) reflects the risk-return tradeoff $A$-investors face. The second term in (3) is the $A$-investors' expected capital gain, and the third term is the cost of bearing dividend risk $\epsilon$. The cost function $f$ depends on $A$-investors' exposure $\left(y_{1}+u\right)$ to that risk. The first order condition is

$$
f^{\prime}\left(y_{1}+u\right)=\phi_{1}
$$

By symmetry, $B$-investors' first-order condition is identical. 
Arbitrageurs. Arbitrageurs can invest in all risky assets as well as in the riskfree asset. Hence, an arbitrageur's budget constraint when he enters $A B$ spread trades (i.e., $x_{1} \equiv x_{A, 1}=-x_{B, 1}>0$ ) is

$$
W_{2}=W_{1}+x_{1}\left(-p_{A, 1}+p_{A, 2}\right)-x_{1}\left(-p_{B, 1}+p_{B, 2}\right)=W_{1}+2 x_{1} \phi_{1} .
$$

The right-hand side of (5) is certain. Indeed, arbitrageurs can eliminate the dividend risk $\epsilon$ by taking opposite positions in assets $A$ and $B$, and exploit any price discrepancy between these assets (i.e., if $\phi_{1}>0$ ).

Each arbitrageur maximizes (5) subject to his financial constraint. To borrow $p_{A, 1}$ and long one share of asset $A$, he must post a haircut $m$ in the riskfree asset covering the maximum drop in asset $A$ 's value by $t=2$ :

$$
m=p_{A, 1}-\min _{\epsilon \in[-\bar{\epsilon},+\bar{\epsilon}]} p_{A, 2}=\left(\bar{\delta}-\phi_{1}\right)-\min _{\epsilon \in[-\bar{\epsilon},+\bar{\epsilon}]}\{\bar{\delta}+\epsilon\}=\bar{\epsilon}-\phi_{1} .
$$

By symmetry, the same holds for short positions in asset $B .{ }^{8}$ Since the haircuts an arbitrageur posts come out of his wealth, the total positions he can take are restricted by his wealth as follows:

$$
2\left(\bar{\epsilon}-\phi_{1}\right) x_{1} \leq W_{1} .
$$

Notice that the financial constraint becomes more severe when the arbitrageurs' wealth $W_{1}$ decreases. It also becomes more severe when the bound $\bar{\epsilon}$ increases because more volatile asset payoffs increase the maximum loss of a position, and therefore the required haircut. Finally, it becomes less severe when $\phi_{1}$ increases because the maximum loss of a position decreases.

Equilibrium. Arbitrageurs must invest as much as possible in the $A B$ spread trade as long as $\phi_{1}>0$, i.e., they "max out" their financial constraint. At the same time, their aggregate spread trade reduces the price wedge $\phi_{1}$. The equilibrium outcome depends on whether arbitrageurs close the price wedge before their financial constraint binds.

Proposition 1 The equilibrium is as follows.

- If $W_{1}<2 \bar{\epsilon} u$, the arbitrageurs' financial constraint binds and markets are illiquid: Assets $A$ and $B$ trade at different prices $\left(\phi_{1}>0\right)$. Market liquidity increases with arbitrage capital $\left(\partial \phi_{1} / \partial W_{1}<0\right)$, and decreases with liquidity demand and dividend volatility $\left(\partial \phi_{1} / \partial u>0, \partial \phi_{1} / \partial \bar{\epsilon}>0\right)$.

- If $W_{1} \geq 2 \bar{\epsilon} u$, the arbitrageurs' financial constraint is slack and market liquidity is perfect: Assets $A$ and $B$ trade at the same price $\left(\phi_{1}=0\right)$.

\footnotetext{
${ }^{8}$ Note that $m>0$. Indeed, if $m \leq 0$, then asset $A$ would never fall in value between $t=1$ and $t=2$. A-investors, who are unconstrained, could then execute an arbitrage at $t=1$ by borrowing at the riskless rate is zero and buying asset $A$.
} 
This result highlights the role of arbitrage capital for market liquidity. Absent financial constraints (i.e., $m=0$ ), markets are perfectly liquid $\left(\phi_{1}=0\right)$ and therefore arbitrage capital plays no role $\left(\partial \phi_{1} / \partial W_{1}=0\right)$. With financial constraints however, market liquidity depends positively on the level of arbitrage capital $\left(\partial \phi_{1} / \partial W_{1}<0\right)$. In particular, liquidity dry-ups correspond to situations in which arbitrage capital is low, i.e., $W_{1}$ small.

Now hold arbitrage capital constant. When liquidity demand is small (i.e., $u \leq W_{1} / 2 \bar{\epsilon}$ ), arbitrageurs can fully absorb it, and provide perfect liquidity. When it is large however, arbitrageurs' limited investment capacity prevents them from supplying enough liquidity. In that case, as liquidity demand increases, more of this demand remains unsatisfied, which is reflected in a wider price wedge $\phi_{1}$.

Finally, consider different levels of dividend volatility $\bar{\epsilon}$. When volatility is low (i.e., $\bar{\epsilon} \leq W_{1} / 2 u$ ), liquidity is perfect independently of dividend volatility. When volatility is high, however, haircuts are high, impairing arbitrageurs' ability to provide liquidity. As a result, liquidity decreases. ${ }^{9}$

Shocks to arbitrage capital are, in part, the result of the performance of past investments. Our model can be extended to incorporate arbitrage dynamics and arbitrage risk, which are important for time series implications. Some insights can, however, be gained from its present version. Suppose that at $t=0$, arbitrageurs have wealth $W_{0}$ and hold positions $x_{0}>0$ and $-x_{0}$ in assets $A$ and $B{ }^{10}$ Suppose further that the liquidity demand $u$ is uncertain as of $t=0$ but known at $t=1{ }^{11}$ Extrapolating from (5), the arbitrageurs' wealth at $t=1$ is easily seen to now be

$$
W_{1}=W_{0}+2 x_{0}\left(\phi_{0}-\phi_{1}\right) .
$$

This setup allows us to examine the link between arbitrageurs' performance and their ability to provide market liquidity. Indeed, (8) illustrates the twoway relationship between arbitrage capital and market liquidity at $t=1$. On one hand, liquidity depends on arbitrage capital (Proposition 1). On the other hand, greater liquidity at $t=1$ translates into greater capital gains $2 x_{0}\left(\phi_{0}-\phi_{1}\right)$ on the arbitrageurs' existing positions, which increases their capital.

\section{Proposition 2}

\footnotetext{
${ }^{9}$ Similar results hold for $\left(\partial \phi_{1} / \partial u\right)^{-1}$, another often used definition of liquidity.

${ }^{10}$ In a full-fledged dynamic model, these would be endogenous.

${ }^{11}$ Beyond liquidity demand uncertainty (liquidity risk), another source of risk may be that assets $A$ and $B$ 's dividends are only imperfectly correlated (fundamental risk).
} 
- If $u \leq\left(W_{0}+2 x_{0} \phi_{0}\right) / 2 \bar{\epsilon}$, arbitrageurs provide perfect market liquidity $\left(\phi_{1}=0\right)$ and hold larger positions in response to larger liquidity demand shocks $\left(\partial x_{1} / \partial u>0\right)$.

- If $u>\left(W_{0}+2 x_{0} \phi_{0}\right) / 2 \bar{\epsilon}$, larger liquidity demand shocks result in lower market liquidity $\left(\partial \phi_{1} / \partial u>0\right)$ and arbitrageurs respond by holding larger positions if $W_{0}+2 x_{0} \phi_{0} \geq 2 \bar{\epsilon} x_{0}$, and smaller ones otherwise.

This result speaks to the question of whether arbitrageurs play a stabilizing or destabilizing role in financial markets. Indeed, this is linked to whether arbitrageurs react to a liquidity demand shock by increasing their positions or by instead liquidating them. In our model, a greater shock $u$ to liquidity demand translates into a wider price wedge. On one hand, the wider price wedge reduces the arbitrageurs' capital gain between $t=0$ and $t=1$, which tightens their financial constraint. On the other hand, the wider price wedge reduces the maximum loss the position can experience between $t=1$ and $t=2$, which relaxes the financial constraint. When the former effect dominates, which occurs if arbitrageurs are heavily invested at $t=0$ (i.e., $x_{0}>W_{0} / 2 \bar{\epsilon}$ ), arbitrageurs are forced to reduce their positions precisely, and somewhat paradoxically, because the arbitrage opportunity is very profitable. Doing so, they push prices further apart, thereby amplifying the shock's effect. In that case, arbitrageurs play a destabilizing role in that they amplify shocks. When the latter effect dominates, arbitrageurs react to the shock by increasing their liquidity supply, thereby dampening the shock's effect. In that case, arbitrageurs play a stabilizing role.

\section{Discussion}

\subsection{Contagion}

The model can be extended to multiple arbitrage opportunities. For instance, consider two pairs of segmented markets, $(A, B)$, and $\left(A^{\prime}, B^{\prime}\right)$, with their respective risky assets and investors. Arbitrageurs will allocate their scarce capital to the opportunity affording them the highest return per unit of capital tied up as collateral. Hence, in equilibrium, the "return on collateral" is equalized across opportunities, i.e., $\phi_{1} / m=\phi_{1}^{\prime} / m^{\prime}$.

One implication is that opportunities with higher margin requirements (e.g., greater volatility) are more illiquid. Indeed, arbitrageurs will demand a higher reward for tying up more capital as collateral. Another implication is that the scarcity of arbitrage capital creates a linkage across otherwise independent markets. Indeed, a negative shock to arbitrageurs' capital forces them to reduce their positions in some markets, reducing 
their liquidity. But returns on collateral equalization means that when arbitrage capital is low, liquidity dries up in all markets, and more so in more volatile ones.

\subsection{Welfare and Policy}

The welfare implications of intermediaries' financial constraints underlie many policy questions. Can a shock to intermediary capital create systemic risk by propagating through the financial system with harmful effects? If yes, should market participants risk-taking be regulated?

In our model, the arbitrageurs' presence benefits all investors by increasing liquidity. Given that liquidity depends on arbitrageur capital, the question is: Do arbitrageurs put their capital at risk in a socially optimal way? We can show that this is generally not the case: Arbitrageurs fail to invest in a constrained socially optimal fashion. The price impact of changing arbitrageurs' positions redistributes wealth among agents in different states. When the arbitrageurs' financial constraints bind, markets remain partially segmented. The resulting market incompleteness implies that agents' marginal rates of substitution need not be equalized. Therefore, a wealth redistribution can create a pecuniary externality, transferring wealth to agents in states in which they need it most, possibly increasing social welfare. Because this externality works through price effects, it is not internalized by competitive agents. Arbitrageurs may put their capital at too much or too little risk (Gromb and Vayanos $(2002,2009 \mathrm{~b})) .{ }^{12}$

This analysis opens the door for a discussion of policy aimed at curbing arbitrageurs' risk-taking. Suppose that arbitrageurs take excessive risk. In our model, eliminating arbitrageurs' financial constraints would ensure efficiency. Suppose instead that this option is not available. One might decrease arbitrageurs' incentives to take risk by tightening their effective financial constraints. This can be implemented with a tax or a capital requirement. Second, rather than inducing arbitrageurs to follow a more socially desirable risk management policy, one might enforce it directly e.g. by taxing them in good times and subsidizing them in bad times. Finally, in our model, competitive arbitrageurs fail to internalize the price effects of their decisions. Imperfect competition among arbitrageurs might lead them to internalize some of the price effects, possibly leading them to adopt investment policies closer to the social optimum.

\footnotetext{
${ }^{12}$ Geanakoplos and Polemarchakis (1986) are the first to derive this externality, in an abstract general-equilibrium setting. Caballero and Krishnamurthy (2001), Lorenzoni (2008) and Korinek (2009) explore the implications of this externality in macroeconomic settings. See also Stiglitz (1982) for an early study of the (lack of) constrained efficiency of competitive equilibrium in incomplete financial markets.
} 


\section{References}

Brunnermeier, Markus, and Lasse Pedersen (2009), "Market Liquidity and Funding Liquidity." Review of Financial Studies, 22, 2201-2238.

Caballero, Ricardo, and Arvind Krishnamurthy (2001), "International and Domestic Collateral Constraints in a Model of Emerging Market Crises." Journal of Monetary Economics, 48, 513-548.

Duffie, Darrell, and Bruno Strulovici (2009), "Capital Mobility and Asset Pricing." Working paper, Stanford University.

Geanakoplos, John (2003), "Liquidity, Default and Crashes: Endogenous Contracts in General Equilibrium." Advances in Economics and Econometrics: Theory and Applications, Eighth World Conference, Volume II, Econometric Society Monographs, 170-205.

Geanakoplos, John (2009), "The Leverage Cycle." NBER Macro Annual.

Geanakoplos, John, and Heraklis Polemarchakis (1986), "Existence, Regularity, and Constrained Suboptimality of Competitive Allocations when the Asset Market is Incomplete." In: Heller, W., Starr, R., Starrett, D. (Eds.) Uncertainty, Information and Communication, Essays in Honor of Kenneth J. Arrow, Vol. 3, Cambridge University Press, Cambridge, UK.

Gromb, Denis, and Dimitri Vayanos (2002), "Equilibrium and Welfare in Markets with Financially Constrained Arbitrageurs." Journal of Financial Economics, 66, 361-407.

Gromb, Denis, and Dimitri Vayanos (2009a), "Financially Constrained Arbitrage and Cross-Market Contagion." Working paper, INSEAD.

Gromb, Denis, and Dimitri Vayanos (2009b), "Leverage and Liquidity Dry-ups: A Framework and Policy Implications." Working paper, INSEAD.

He, Zhiguo, and Arvind Krishnamurthy (2009a), "Intermediation, Capital Immobility, and Asset Prices." Working paper, University of Chicago.

He, Zhiguo, and Arvind Krishnamurthy (2009b), "Intermediary Asset Pricing." Working paper, University of Chicago.

Kondor, Péter (2009), "Risk in Dynamic Arbitrage: Price Effects of Convergence Trading." Journal of Finance, 64, 638-658.

Korinek, Anton (2009), "Systemic Risk Taking: Amplification Effects, Externalities, and Regulatory Responses." Working paper, University of Maryland.

Kyle, Albert S., and Wei Xiong (2001), "Contagion as a Wealth Effect of Financial Intermediaries." Journal of Finance, 56, 1401-1440.

Lorenzoni, Guido (2008), "Inefficient Credit Booms." Review of Economic Studies, 75, 809-833. 
Pavlova, Anna, and Roberto Rigobon (2008), "The Role of Portfolio Constraints in the International Propagation of Shocks." Review of Economic Studies, 75, 1215-1256.

Shleifer, Andrei, and Robert W. Vishny (1997), "The Limits of Arbitrage." Journal of Finance, 52, 35-55.

Stiglitz, Joseph E. (1982), "The Inefficiency of the Stock Market Equilibrium," Review of Economic Studies, 49, 241-261.

Tuckman, Bruce and Jean-Luc Vila (1992), "Arbitrage with Holding Costs: A Utility-Based Approach." Journal of Finance, 47, 1283-1302.

Vayanos, Dimitri, and Jiang Wang (2009), "Theories of Liquidity." Foundations and Trends in Finance, forthcoming.

Xiong, Wei (2001), "Convergence Trading with Wealth Effects." Journal of Financial Economics, 62, 247-292.

\section{Appendix}

Proof of Proposition 1: We first determine when arbitrageurs can close the price wedge, i.e., $\phi_{1}=0$. From market clearing and (4), $\phi_{1}=0$ implies $f^{\prime}\left(u-x_{1}\right)=0$. Since $f^{\prime \prime}>0$ and $f^{\prime}(0)=0$ (because $f$ is symmetric around the $y$-axis), this yields $x_{1}=u$. Eq. (7) then implies $W_{1} \geq 2 \bar{\epsilon} u$. If instead $W_{1}<2 \bar{\epsilon} u$, arbitrageurs cannot close the price wedge, i.e., $\phi_{1}>0$. Therefore, they max out their financial constraint, i.e., $W_{1}=2\left(\bar{\epsilon}-\phi_{1}\right) x_{1}$. Market clearing and (4) imply that $\phi_{1}=f^{\prime}\left(u-\frac{W_{1}}{2\left(\bar{\epsilon}-\phi_{1}\right)}\right)>0$. Since $f^{\prime}$ is increasing, $\phi_{1}$ is decreasing in $W_{1}$, and is increasing in $u$ and $\bar{\epsilon}$.

Proof of Proposition 2: We first determine when arbitrageurs can close the price wedge, i.e., $\phi_{1}=0$. From Proposition 1, this happens if $W_{1} \geq 2 \bar{\epsilon} u$. Since $W_{1}=W_{0}+2 x_{0}\left(\phi_{0}-\phi_{1}\right)$, the condition becomes $W_{0}+2 x_{0} \phi_{0} \geq$ $2 \bar{\epsilon} u$. The arbitrageurs' position is $x_{1}=u$ and increases in $u$. If instead $W_{0}+2 x_{0} \phi_{0}<2 \bar{\epsilon} u$, arbitrageurs cannot close the price wedge. Since they max out their financial constraint,

$$
x_{1}=\frac{W_{1}}{2\left(\bar{\epsilon}-\phi_{1}\right)}=\frac{W_{0}+2 x_{0}\left(\phi_{0}-\phi_{1}\right)}{2\left(\bar{\epsilon}-\phi_{1}\right)} .
$$

Eq. (9) implies that $x_{1}$ increases in $\phi_{1}$ if $W_{0}+2 x_{0} \phi_{0} \geq 2 \bar{\epsilon} x_{0}$, and decreases otherwise. The price wedge is determined by

$$
\phi_{1}=f^{\prime}\left(u-\frac{W_{0}+2 x_{0}\left(\phi_{0}-\phi_{1}\right)}{2\left(\bar{\epsilon}-\phi_{1}\right)}\right) .
$$

Implicit differentiation of (10) yields that $\phi_{1}$ is increasing in $u$. Therefore, $x_{1}$ increases in $u$ if $W_{0}+2 x_{0} \phi_{0} \geq 2 \bar{\epsilon} x_{0}$, and decreases otherwise. 